\title{
Iron-containing phases in fly ashes from different combustion systems
}

Tadeusz Szumiata, Małgorzata Gzik-Szumiata, Katarzyna Brzózka, Bogumil Górka, Michal Gawroński, Ryszard Swietlik, Marzena Trojanowska

\begin{abstract}
The investigations of iron-containing phases existing in fly ashes were performed using transmission Mössbauer spectrometry. The examined samples of fly ashes were collected from different coal combustion systems, that is, stoker-fired boiler in municipal heating plant and pulverized coal boiler in power plant. Several phases are identified in the samples: iron oxides, paramagnetic aluminosilicate glass with $\mathrm{Fe}^{3+}$ ions and $\mathrm{Al}_{2} \mathrm{O}_{4-}$ -type spinel with $\mathrm{Fe}^{2+}$ ions. It was pointed out that proportions of contents of phases strongly depend not only on the combustion temperature but also on the way of ash collection.
\end{abstract}

Key words: fly ashes $\bullet$ coal combustion $\bullet$ Mössbauer spectrometry $\bullet$ environmental protection

T. Szumiata ${ }^{\bowtie}$, M. Gzik-Szumiata, K. Brzózka, B. Górka, M. Gawroński

Department of Physics,

University of Technology and Humanities in Radom,

54 Krasickiego Str., 26-600 Radom, Poland,

E-mail: t.szumiata@uthrad.pl

R. Świetlik, M. Trojanowska

Department of Environmental Protection,

University of Technology and Humanities in Radom,

27 Chrobrego Str., 26-600 Radom, Poland

Received: 18 June 2014

Accepted: 2 November 2014

\section{Introduction}

Mössbauer spectrometry has recently been utilized in structural and magnetic properties analysis of fly ashes, road dusts, fly ash-recycled glass, and metallurgical slags [1-6]. This method has proved to be a very effective tool in the environmental protection studies due to the high sensitivity and precision of phase analysis. The most common ${ }^{57} \mathrm{Fe}$-based Mössbauer measurements allow determining a content of iron-bearing phases, which are frequently accompanied by heavy metals - the most serious environmental pollutants.

Presented studies are an extension of our preliminary work [1] devoted to the coal ashes coming from two different combustion systems: stoker-fired boiler and pulverized coal boiler of significantly different combustion temperatures. The main goal of the present work was to find out how the phase content of fly ashes depends not only on the combustion temperature but also on the procedure of fly ash collection carried out by means of different types of devices. Various fractions of fly ashes can be intentionally introduced into the environment and utilized in different ways.

\section{Experiment}

Two samples of fly ashes (named P3 and P4) from the stoker-fired boiler were the first object of the investigation. This kind of mechanical stoker system is widely utilized in heating plants. Moving chain grate increases combustion efficiency and comfort of the operation. The temperature of burning zone was about $1100^{\circ} \mathrm{C}$. The solid particles suspended in 
a flue gas were removed by means of multicyclone device, which consists of a housing containing a quantity of centrifugal dust collecting tubes. Sample P3 represents the first fraction of fly ash (collected by multicyclone device) with grains of the average diameter $\phi>63 \mu \mathrm{m}$, whereas $\mathrm{P} 4$ sample comes from the second fraction, in which $\phi<63 \mu \mathrm{m}$.

Next three samples (P6, P7, P8) were the ashes from pulverized coal boiler of noticeably higher temperature of burning zone $\left(1800-1900^{\circ} \mathrm{C}\right)$. Such type of boiler is a standard combustion system used in thermal power plants for generating electricity. In this boiler, coal is ground to the size of a fine grain, mixed with air and burned in the flue gas flow. The main idea of using pulverized fuel is to obtain the effect of whole volume combustion of solid fuels in furnace. After combustion, the fly ashes were trapped by electrostatic precipitator (ESP). In the ESP device, the gas passes first through an electrically charged screen that gives a charge to the particles, then between two charged plates where the particles are attracted to one of the surfaces. Usually, the ESP system consists of three sections that are connected serially. A specific surface of fly ash particles increases in the direction of successive ESP sections due to the decreasing volume and size of grains. The samples P6, P7, and P8 correspond to the Ist, IInd and IIIrd section of ESP, respectively.

For each sample, the so-called pseudo-total content of iron was determined using a standard procedure of sample digestion in strong acids that do not dissolve the silicate matrix. Pseudo-total content analysis is a very common procedure utilized in environmental chemistry for the fast estimate of maximum amounts of metals.

Standard ${ }^{57} \mathrm{Fe}$ transmission Mössbauer spectrometry has been applied at room temperature for identifications of iron-containing phases in the investigated samples of fly ashes. The vertically configured spectrometer was operating in constant acceleration mode with 1024 time-resolved channels. The time of Mössbauer spectrum collection was typically 1 week using Co(Rh) Mössbauer source of $50 \mathrm{mCi}$ activity. The Mössbauer spectra were fitted with Voigt-type functions (as convolution of Lorentzian-lined Zeeman sextets with Gaussian hyperfine field distributions) by means of self-prepared
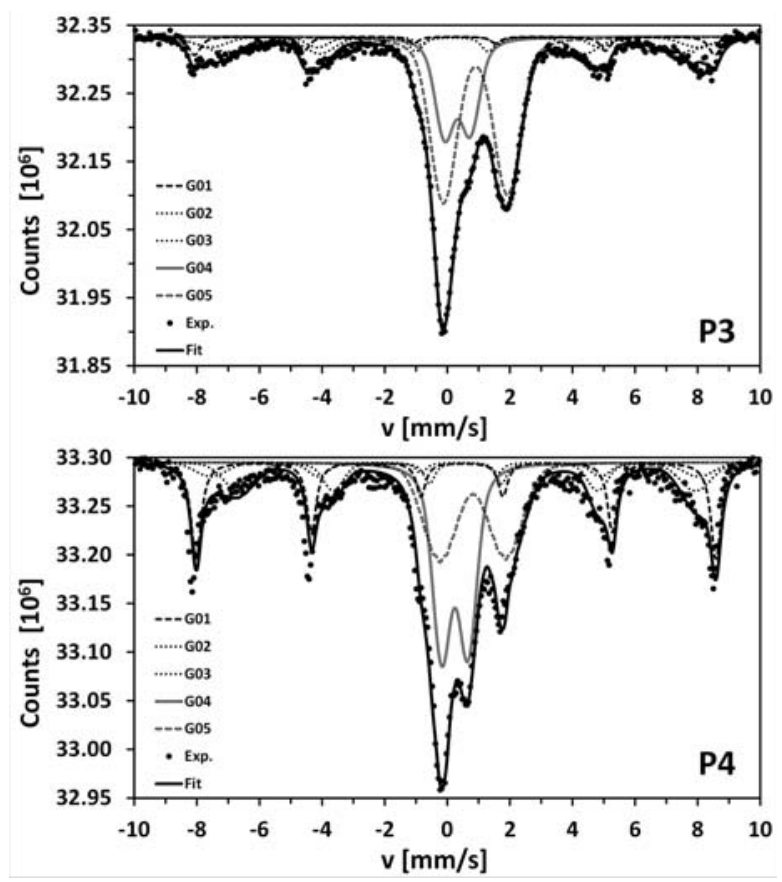

Fig. 1. The Mössbauer spectra of fly ash from stoker-fired boiler, collected in multicyclone device: (top) fraction of grain size: $\phi>63 \mu \mathrm{m}$; (bottom) fraction of grain size: $\phi<63 \mu \mathrm{m}$ (samples: P3 and P4, respectively).

PolMöss software utilizing multithreading features of MS Excel and Solver component with gradient as well as evolutionary optimization. PolMöss package was introduced for the first time and applied with success for detailed analysis of complex Mössbauer spectra of disordered Fe-Ga thin layers [7, 8].

\section{Results and discussion}

In Fig. 1, the Mössbauer spectra for P3 and P4 samples are presented, that is, for two fractions of fly ash from stoker-fired boiler collected in multicyclone device. The pseudo-total content of iron in these two samples is equal $(15.8 \pm 1.2) \mathrm{g} / \mathrm{kg}$ and $(25.6 \pm 1.0) \mathrm{g} / \mathrm{kg}$, respectively. The values of parameters of the fitted Mössbauer spectra are given in Table 1: component's contribution $P$, mean value of isomer shift IS $\mathrm{I}_{0}$ related to $\alpha$-Fe, width of isomer shift distribution $D(\mathrm{IS})$, quadrupole splitting $\mathrm{QS}_{0}$, mean

Table 1. Hyperfine parameters of the Mössbauer spectra of fly ash from stoker-fired boiler, collected in multicyclone device: a) fraction of grain size $\phi>63 \mu \mathrm{m}, \mathrm{b}$ ) fraction of grain size $\phi<63 \mu \mathrm{m}$ (samples: P3 and P4, respectively)

\begin{tabular}{lccccrrr}
\hline Sample & Component & $\begin{array}{c}P \\
{[\%]}\end{array}$ & $\begin{array}{c}\mathrm{IS}_{0} \\
{[\mathrm{~mm} / \mathrm{s}]}\end{array}$ & $\begin{array}{c}D(\mathrm{IS}) \\
{[\mathrm{mm} / \mathrm{s}]}\end{array}$ & $\begin{array}{c}\mathrm{QS}_{0} \\
{[\mathrm{~mm} / \mathrm{s}]}\end{array}$ & $\begin{array}{c}B_{0}=<B_{\mathrm{hf}}> \\
{[\mathrm{T}]}\end{array}$ & $\begin{array}{c}D\left(B_{\mathrm{hf}}\right) \\
{[\mathrm{T}]}\end{array}$ \\
\hline \multirow{4}{*}{ a) P3 } & $\mathrm{G} 01$ & 6 & 0.31 & 0.00 & 0.00 & 51.7 & 0.5 \\
& $\mathrm{G} 02$ & 8 & 0.42 & 0.00 & -0.15 & 48.5 & 2.9 \\
& $\mathrm{G} 03$ & 16 & 0.26 & 0.00 & 0.06 & 45.4 & 4.3 \\
& $\mathrm{G} 04$ & 22 & 0.43 & 0.22 & 0.81 & 0.0 & 0.0 \\
& $\mathrm{G} 05$ & 48 & 1.01 & 0.34 & 2.05 & 0.0 & 0.0 \\
b) P4 & $\mathrm{G} 01$ & 25 & 0.37 & 0.00 & -0.19 & 51.7 & 0.3 \\
& $\mathrm{G} 02$ & 6 & 0.31 & 0.00 & -0.15 & 48.5 & 2.6 \\
& $\mathrm{G} 03$ & 13 & 0.61 & 0.00 & 0.06 & 45.4 & 2.6 \\
& $\mathrm{G} 04$ & 30 & 0.35 & 0.21 & 0.84 & 0.0 & 0.0 \\
\hline
\end{tabular}


value of magnetic hyperfine field $B_{0}=\left\langle B_{\mathrm{hf}}>\right.$ and width of hyperfine field distribution $D\left(B_{\mathrm{hf}}\right)$. The percentages $P$ is a ratio of iron contribution in specified phase or sublattice to the total amount of iron. The sextet G01 of the highest hyperfine field corresponds to hematite. Next two sextets (G02 and G03) represent two inequivalent positions of iron in magnetite, that is, $\mathrm{Fe}^{3+}$ and $\mathrm{Fe}^{2.5+}$, respectively, where the ratio of abundances is following G03/G02 = 2. Two predominating components (doublets G04 and G05) have already been reported in [9], but ambiguously attributed to one glassy phase. Nevertheless, later papers [10] and [11] gave conclusive phase evidence. The doublet G04 corresponds to iron-containing paramagnetic aluminosilicate glass identified as mullite (porcellanite, $\mathrm{Al}_{6} \mathrm{Si}_{2} \mathrm{O}_{13}$ ) with $\mathrm{Fe}^{3+}$ ions. The doublet $\mathrm{G} 05$ of much higher isomer shift and quadrupole splitting values represents a phase with $\mathrm{Fe}^{2+}$ ions and recognized as hercynite $\left(\mathrm{Fe}^{2+} \mathrm{Al}_{2} \mathrm{O}_{4}\right.$ spinel).

The widths of hyperfine field distributions $D\left(B_{\mathrm{hf}}\right)$ in magnetic oxides as well as widths $D$ (IS) of isomer shift distributions for both paramagnetic components are considerably broadened pointing to chemical disorder, structural distortions, and surface defects in fine grains of ashes. Another sign of such effects is a large dispersion of fitted values of IS and QS for iron oxides. An additional reason for the spread of parameters values could be the presence of other oxides, for example, maghemite. In the analyzed Mössbauer spectra, the 3:2:1 ratio of line intensities in Zeeman sextets confirms the absence both of magnetic and polycrystalline texture, which is typical for powder samples.

The most crucial result concerning two investigated samples of ashes from stoker-fired boiler is the fact that for finer fraction of ashes (second section of multicyclone system), the ratio of aluminosilicate glass phase contribution (with $\mathrm{Fe}^{3+}$ ions) to the content of hercynite spinel with $\mathrm{Fe}^{2+}$ ions is more than 2.5 times higher than in the case of larger grains fraction (first multicyclone section). It is also accompanied by more than 5 times greater contribution a

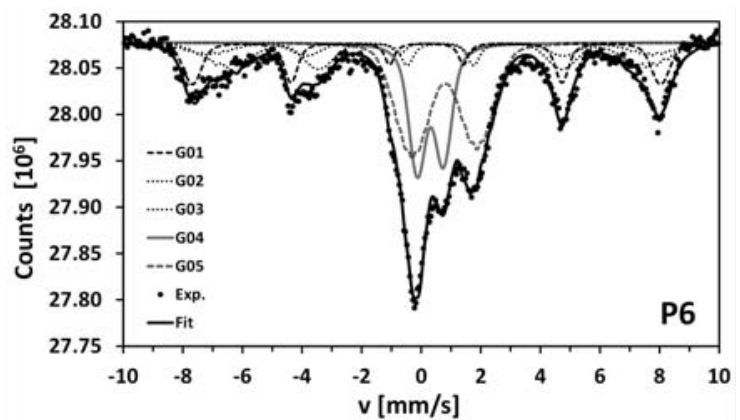

b

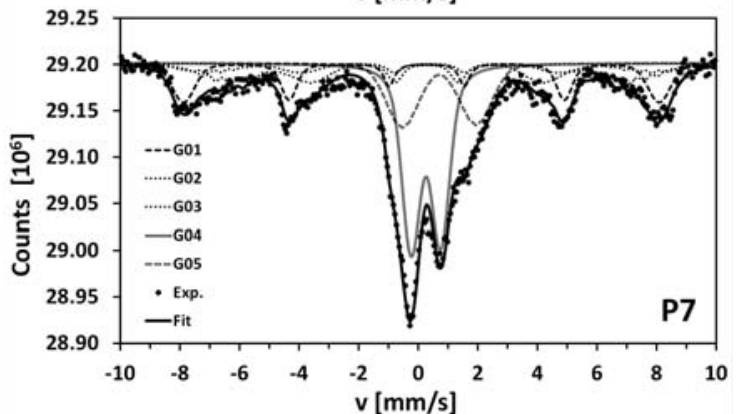

c

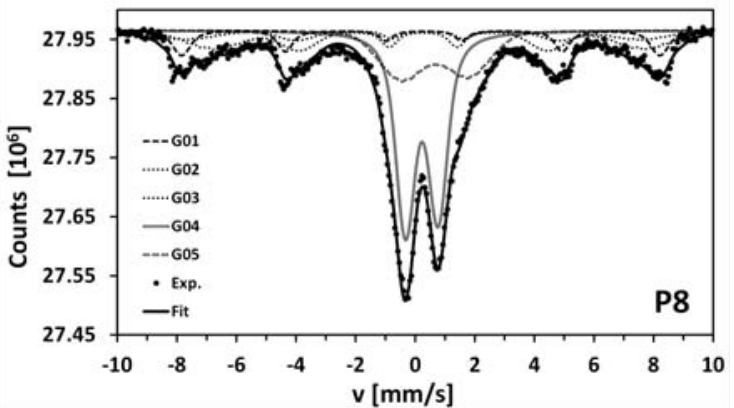

Fig. 2. The Mössbauer spectra of fly ash from pulverized coal boiler, collected in a) Ist, b) IInd and c) IIIrd section of electrostatic precipitator system (samples: P6, P7 and $\mathrm{P} 8$, respectively).

of magnetite relative to hematite, whereas the total content of iron oxides increases about 1.5 times.

The Mössbauer spectra of three fly ash samples (P6, P7, P8) from pulverized coal boiler collected by ESP device, and corresponding hyperfine parameters, are displayed in Fig. 2 and Table 2, respectively. The

Table 2. Hyperfine parameters of the Mössbauer spectra of fly ash from pulverized coal boiler, collected in a) Ist; b) IInd and c) IIIrd field of electrostatic precipitator system (samples: P6, P7 and P8, respectively)

\begin{tabular}{lccccrrr}
\hline Sample & Component & $\begin{array}{c}P \\
{[\%]}\end{array}$ & $\begin{array}{c}\mathrm{IS}_{0} \\
{[\mathrm{~mm} / \mathrm{s}]}\end{array}$ & $\begin{array}{c}D(\mathrm{IS}) \\
{[\mathrm{mm} / \mathrm{s}]}\end{array}$ & $\begin{array}{c}\mathrm{QS}_{0} \\
{[\mathrm{~mm} / \mathrm{s}]}\end{array}$ & $\begin{array}{c}B_{0}=<B_{\mathrm{hf}}> \\
{[\mathrm{T}]}\end{array}$ & $\begin{array}{c}D\left(B_{\mathrm{hf}}\right) \\
{[\mathrm{T}]}\end{array}$ \\
\hline \multirow{4}{*}{ a) P6 } & G01 & 16 & 0.29 & 0.00 & 0.00 & 48.9 & 1.4 \\
& $\mathrm{G} 02$ & 10 & 0.48 & 0.00 & -0.16 & 46.4 & 4.4 \\
& $\mathrm{G} 03$ & 20 & 0.69 & 0.00 & -0.11 & 43.9 & 4.4 \\
& G04 & 21 & 0.42 & 0.20 & 0.88 & 0.0 & 0.0 \\
b) P7 & G05 & 33 & 0.89 & 0.50 & 2.18 & 0.0 & 0.0 \\
& G01 & 18 & 0.31 & 0.00 & -0.18 & 49.7 & 1.8 \\
& G02 & 9 & 0.49 & 0.00 & 0.00 & 46.5 & 5.7 \\
& G03 & 19 & 0.45 & 0.00 & 0.10 & 41.9 & 5.7 \\
c) P8 & G04 & 35 & 0.37 & 0.22 & 0.99 & 0.0 & 0.0 \\
& G05 & 19 & 0.82 & 0.45 & 2.48 & 0.0 & 0.0 \\
& G01 & 11 & 0.35 & 0.00 & -0.11 & 50.0 & 1.0 \\
& G02 & 10 & 0.28 & 0.00 & -0.48 & 47.5 & 5.3 \\
& G03 & 19 & 0.37 & 0.00 & 0.19 & 45.0 & 5.3 \\
\end{tabular}


pseudo-total content of iron in these samples is following: $(18.2 \pm 1.2) \mathrm{g} / \mathrm{kg},(17.7 \pm 1.0) \mathrm{g} / \mathrm{kg}$ and $(16.8 \pm 1.0) \mathrm{g} / \mathrm{kg}$. The phase composition of these samples is similar to the case of previous ash samples; however, the relative contents are very specific. The total contributions of iron oxides do not vary significantly from sample to sample, staying at the level of about $40-45 \%$. The ratio of the content of glass phase to spinel phase increases more than three times when going from the first to third section of ESP, which corresponds to finer fraction of fly ash. This higher content of glassy phase, when the grains are smaller, is consistent with the same tendency for fly ash from stoker-fired boiler. Nevertheless, the ratio of the average contribution of $\mathrm{Fe}^{3+}$-containing phase to $\mathrm{Fe}^{2+}$-containing phase seems to be higher in the case of the fly ash from pulverized coal boiler of higher temperature in burning zone.

\section{Conclusions}

The performed investigations have clearly shown that in the studied fly ashes, the proportion of glassy-phase content to spinel-phase content strongly depends not only on the combustion temperature but first of all on the grain fraction originating from respective section of fly ash collecting devices. In both combustion systems higher relative content of glassy phase occurs in samples of ash with finer grains (i.e. particles of higher specific surface), which are collected in successive sections of multicyclone device or electrostatic precipitator. In the case of the ash from stoker-fired boiler, this content increases 2.5 times and in the case of pulverized coal boiler - even three times. The observed increase is accompanied by augmentation of iron oxide contribution only in stoker-fired boiler ash. A significant dispersion of hyperfine parameters of the Mössbauer spectra can be related to the fact that ash particles originating in coal combustion process in power plants take various morphological forms of different sizes and structure such as glass microspheres, cenospheres, and magnetospheres [12].

\section{References}

1. Szumiata, T., Brzózka, K., Górka, B., Gawroński, M., Gzik-Szumiata, M., Świetlik, R., \& Trojanowska, M. (2014). Iron speciation in coal fly ashes - chemical and Mössbauer analysis. Hyperfine Interact., 226, 483-487. DOI: 10.1007/s10751-013-0950-2.

2. Szumiata, T., Gawroński, M., Górka, B., Brzózka, K., Świetlik, R., Trojanowska, M., \& Strzelecka, M. (2013). Chemical, magnetic and Mössbauer effect analysis of road dust from expressway. Nukleonika, 58, 107-110.

3. Bajukov, O. A., Anshits, N. N., Petrova, M. I., Balaev, A. D., \& Anshits, A. G. (2009). Composition of ferrospinel phase and magnetic properties of microspheres and cenospheres from fly ashes. Mater. Chem. Phys., 114, 495-503. DOI: 10.1016/j. matchemphys.2008.09.061.

4. Nishida, T., Tokunaga, M., Sugata, Y., \& Kubuki, S. (2005). Mössbauer study of semiconducting and ferrimagnetic fly ash-recycled glass. J. Radioanal. Nucl. Chem., 266, 171-177. DOI: 10.1007/s10967005-0889-0.

5. Jończy, I., \& Stanek, J. (2013). Phase composition of metallurgical slag studied by Mössbauer spectroscopy. Nukleonika, 58, 127-131.

6. Gomes, S., François, M., Abdelmoula, M., Refait, Ph., Pellissier, C., \& Evrard, O. (1999). Characterization of magnetite in silico-aluminous fly ash by SEM, TEM, XRD, magnetic susceptibility, and Mössbauer spectroscopy. Cement. Concr. Res., 29, 1705-1711. DOI: 10.1016/S0008-8846(99)00133-7.

7. Javed, A., Szumiata, T., Morley, N. A., \& Gibbs, M. R. J. (2010). An investigation of the effect of structural order on magnetostriction and magnetic behaviour of Fe-Ga thin films. Acta Mater., 58, 4003-4011. DOI: 10.1016/j.actamat.2010.03.023.

8. Szumiata, T., Górka, B., Brzózka, K., Gawroński, M., Gzik-Szumiata, M., Javed, A., Morley, N. A., \& Gibbs, M. R. J. (2013). Mössbauer study of vacuum annealed $\mathrm{Fe}_{100-x} \mathrm{Ga}_{x}(10 \leq x \leq 35)$ thin films. Nukleonika, 58, 25-28.

9. Taneja, S. P. (2004). Mössbauer studies of thermal power plant coal and fly ash. Hyperfine Interact., 153,83-90. 10.1023/B:HYPE.0000024715.55347.fe.

10. Vandenberghe, R. E., de Resende, V. G., \& De Grave, E. (2009). Mössbauer effect study of fly and bottom ashes from an electric generating plant. Hyperfine Interact., 191, 11-16. DOI: 10.1007/s10751-0099978-8.

11. Vandenberghe, R. E., de Resende, V. G., da Costa, G. M., \& De Grave, E. (2010). Study of loss-on-ignition anomalies found in ashes from combustion of iron-rich coal. Fuel, 89, 2405-2410. DOI: 10.1016/j. fuel.2010.01.022.

12. Zyryanov, V. V., Petrov, S. A., \& Matvienko, A. A. (2011). Characterization of spinel and magnetospheres of coal fly ashes collected in power plants in the former USSR. Fuel, 90, 486-492. DOI: 10.1016/j. fuel.2010.10.006. 